\title{
SCIENCE:
}

A WEERLY NEWSPAPER OF ALL THE ARTS AND SCIENCES.

PUBLISHED BY

N. D. C. HODGES,

87. BRoAdwAy, NeW York.

Stbscriptions.-United States and Canada $\ldots \ldots \ldots \ldots \ldots .50$ a year.
Great Britain and Europe............ 4.50 a year.

Communications will be welcomed from any quarter. A bstracts of scientific papers are solicited, and one hundred copies of the issue containing such will be mailed the author on request in advance. Rejected manuscripts will be returned to the authors only when the requisite amount of postage accompanies the manuscript. Whatever is intended for insertion must be authenticated by the name and address of the writer; not necessarily for publication, but as a guaranty of good faith. We do not hold ourselves responsible for any view or opinions expressed in the communications of our correspondents.

Attention is called to the "Wants" column. It is invaluable to those who use it in soliciting information or seeking new positions. The name and address of applicants should be given in full, so that answers will go direct to them. The "Exchange" column is likewise open.

For Advertising Rates apply to Henry F. Taylor, 13 Astor Place, New York.

\section{LION BREEDING.}

BY DR. V. BALL, C.B., F.R.S , HONORARY SECRETARY ROYAL ZOOLOGICAL SOCIETY OF IRELAND.

THE breeding of lion cubs commenced in the gardens of the Royal Zoological Society of Ireland in the year 185\%, and has been continued through an unbroken descent to the end of 1891, or for thirty-five years; from which, if we subtract the five years from 1874 to 1878 , inclusive - when there was no breeding lioness in the gardens and no cubs were born - the actual period of breeding lasted only thirty years, during which the arerage number of births has been 5.3 per annum.

Parents of the Cubs.

\section{MALES}

No. of Cubs.

\section{FEMALES.}

No. of Cubs.

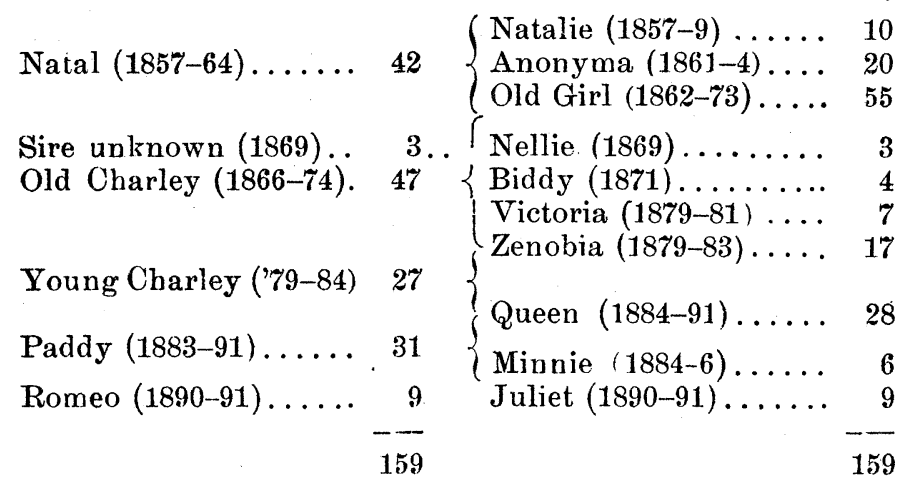

Sexes of the Cubs.

Males.......... $85 \quad$ Females........ 73

Unknown ........ 1 Forward............. 86

Percentage of males to females 53.8 to 46.2 , or a majority of 7.6 males out of every 100.
The Number of Cubs in a Litter.

Total number of litters, 43; number of cubs, 159; average number of cubs in each litter, 3.7 .

Of litters of 6 cubs there were 2

$\begin{array}{rrrrrr}\text { ، } & \text { 6 } & 5 & 6 & 6 & 8 \\ \text { ، } & \text { 6 } & 4 & 6 & 6 & 17 \\ \text { 6 } & 3 & 3 & 6 & 6 & 9 \\ \text { ، } & 2 & 6 & 6 & 5 \\ & \text { ، } & 1 & 6 & 6 & 2\end{array}$

Thus it will be seen that the average number of cubs in a litter approximates most nearly to 4 .

\section{Months in which the Cubs were Born.}

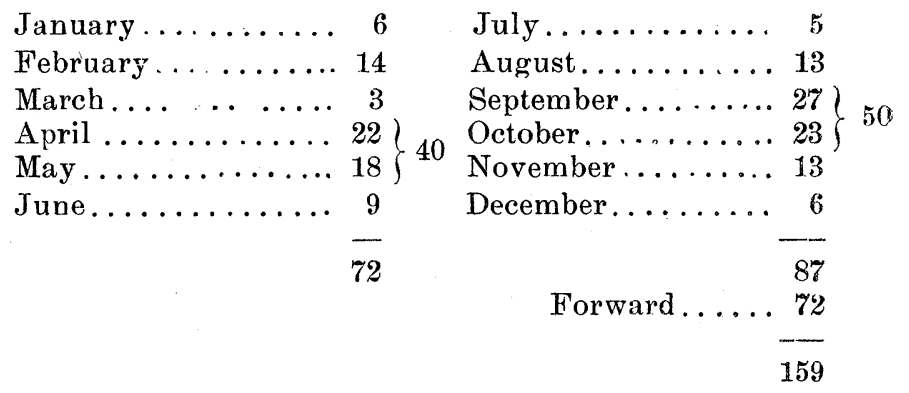

It is to be remarked that 90 out of the total of 159 were born in the four paired months, namely, April and May (40) and September and October (50). These amount to 56.6 per cent of the whole number, leaving only 43.4 per cent for the remaining eight months.

\section{Disposal of the Cubs.}

Died at, or shortly after, birth ............. 30

" after some months or year............. 12

Retained for stock ................... 8

Sold (yielding upwards of $£ 4,000) \ldots \ldots \ldots \ldots \ldots \ldots \ldots \ldots$

\section{THE PURIFICATION OF WATER BY CHEMICAL TREATMENT. ${ }^{1}$ \\ BY WILLIS G, TUCKER, M.D.}

Pure water does not exist in nature. It is an ideal substance to which the purest water that can be prepared by the chemist only approximates. From a chemical standpoint every foreign substance which water may contain is an impurity, but, hygienically considered, water is called impure only when it contains excessive amounts of mineral matter in solution or in suspension; when it contains organic matter of vegetable or animal origin, or the products of the decomposition of such matter in quantities exceeding certain generally accepted but rather arbitrarily assigned limits, or when it is shown to contain living organisms believed to be associated with or productive of diseases which water may communicate. All filth in food or drink is to be abhorred, but, none the less, distinction must be made between that which, containing or accompanying specific disease germs, may give rise to specific diseases, and that which is, while not unobjectionable, yet apparently incapable of materially affecting health. The chemist is as yet unable to distinguise diseaseproducing from relatively harmless impurities in water. He can recognize those constituents which indicate organic pollution; demonstrate the present existence of putrescent material, or show that such material has previously existed

1 Read before the Medical Society of the County of Albany at a meeting held February 23, 1892. Reprinted from the Albany Medical Annals. Apri?, 1892 . 